\title{
Bazı Lacertidlerde (Lacerta trilineata s.l., Parvilacerta parva, Ophisops elegans) Karşılaştırmalı Yaş Tayini
}

\author{
Çiğdem KAPLAN ${ }^{1}$, Cemal Varol TOK ${ }^{2 *}$ \\ *Sorumlu yazar: cvtok@comu.edu.tr \\ ${ }^{1}$ Çanakkale Onsekiz Mart Üniversitesi, Fen Edebiyat Fakültesi, Biyoloji Bölümü, ÇANAKKALE \\ Orcid No: 0000-0001-9323-9157 / cigdemkaplan95@gmail.com \\ 2* Çanakkale Onsekiz Mart Üniversitesi, Fen Edebiyat Fakültesi, Biyoloji Bölümü, ÇANAKKALE \\ Orcid No: 0000-0002-7153-8743 / cvtok@comu.edu.tr
}

\begin{abstract}
Öz: Yapılan çalışmada, Türkiye'nin Konya iline bağlı Akşehir ve civarından toplanmış olan ve Çanakkale Onsekiz Mart Üniversitesi ZDEU-ÇOMÜ Koleksiyonu'nda bulunan örnekler kullanılmıştır. Lacertidae familyasına ait üç türden toplamda 30 birey (Lacerta trilineata $5 \hat{\jmath} \hat{\jmath}, 5$ juvenil; Ophisops elegans $5 \hat{\jmath} \widehat{\jmath}, 5$ 우웅


iskelet kronolojisi yöntemi ile karşılaştırma yapılıp, kemiklere göre yaş halkalarının sayılarında herhangi bir fark olup olmadığına bakılarak, bireylerin mevcut yaşları tespit edilmiştir. Bu türler içerisinde Lacerta trilineata türüne ait 5 juvenil örnekte yaş 2 yıl, 5 erkek örnekte ise yaşlar 5-8 arasında değişmektedir. Parvilacerta parva erkek örneklerinde yaşlar 4-6 arasında, dişilerde ise 4 ve 5 olarak değişmektedir. Ophisops elegans erkek örneklerinde yaşlar 4-6 arasında, dişi örneklerde ise 5-7 arasında değiştiği tespit edilmiştir. Her üç türdeki tüm örneklerde kesit alınıp incelenen üç farklı kemikte de benzer yaşlar bulunmuştur. Kemiklerin yaş halkaları arasındaki bu benzerlik sebebiyle söz konusu türler ile ilgili yapılacak olan yaş çalışmalarında örneklerin öldürülmeden sadece falanjları ile çalışılabileceği düşünülmektedir. Böylece insan faaliyetleri ve değişen çevre faktörleri nedeniyle zarar gören türlerin bu çalışmalardan olumsuz yönde etkilenmesinin önüne geçilmiş olunacaktır.
\end{abstract}

Anahtar Kelimeler: Yaş tayini, İskelet kronolojisi, Lacertidae, Lacerta trilineata, Ophisops elegans, Parvilacerta parva

\section{Comparative Age Determination in Some Lacertids (Lacerta trilineata s.l., Ophisops elegans, Parvilacerta parva)}

\footnotetext{
Abstract: In the study, the samples collected from Akşehir, Konya, Turkey and stored in the Çanakkale Onsekiz Mart University, ZDEU-COMU collection were used. Thirty lizards belonging to the family Lacertidae


evaluated. The age of the individuals was estimated after phalanges, femurs, and humeri samples were compared whether if there is any difference in terms of skeletochronological method. Among these species, the age is 2 years in 5 juvenile specimens of Lacerta trilineata and the ages of 5 males vary between 5 and 8 . The age of male specimens of Parvilacerta parva vary between 4 and 6, and the age of females vary between 4 and 5 . The age of male Ophisops elegans specimens vary between 4 and 6, and the age of females vary between 5 and 7 . Similar ages were found in all three different bones that were sectioned and examined in all samples of all three species. Due to this similarity between the LAGs in the cross-sections of the bones, it is thought that phalanges could be used to determine ages without killing the specimens. In this way, the species that are already damaged due to human activities and changing environmental factors will be prevented from being adversely affected by these studies.
}

Keywords: Age estimation, Skeletochronology, Lacertidae, Lacerta trilineata, Ophisops elegans, Parvilacerta parva 


\section{Giriş}

Lacertidae familyası; Eski Dünya'da (Asya, Avrupa ve Afrika) ve Yeni Dünya'da (Kuzey Amerika'da 5 tür) yayılmış, şu an için tür sayısı 300 kadar olan geniş bir ailedir (Lacerta.de, 2021). Türkiye'de bulunan kertenkelelerin büyük çoğunluğu bu familyaya dahildir (Başoğlu ve Baran, 1977). Lacerta trilineata (İri Yeşil Kertenkele), Türkiye'de, Orta Anadolu'nun batısından itibaren tüm Batı Anadolu Bölgesi'nde dağılış gösterir (Yaşar ve ark., 2021). Parvilacerta parva (Cüce Kertenkele); Türkiye'nin Bat1, Orta ve Doğu Anadolu Bölgelerinde dağılış göstermektedir (Yaşar ve ark., 2021). Ophisops elegans (Tarla Kertenkelesi) ise Türkiye'nin Doğu Karadeniz Bölgesi hariç hemen hemen her yerinde dağılış göstermektedir (Baran ve ark., 2012). Bu üç tür de IUCN Kırmızı Listesi'nde LC (Least Concern/Düşük Riskli) kategorisinde yer alır (IUCN, 2021).

Yaş tayini metodu, pek çok canlı türünün yaşını belirlemek için kullanılan bir metottur. Sadece canlının yaşını belirlemek için değil aynı zamanda büyümesini, gelişmesini, yaşam süresini, üreme yaşını ve onları etkileyen çevresel etkenleri de öğrenmek için kullanılabilmektedir (Üzüm, 2006). Kertenkelelerde bu metot için en güvenilir yöntem "İskelet Kronolojisi" yöntemidir ve bu yöntemde kertenkeleden alınan kısa ve uzun kemiklerde yaş halkaları tespit edilir ve canlının yaşı bu halkalar sayılarak belirlenmiş olur (Yakın, 2012).

Türkiye'de ve Dünya'da kertenkelelerde yaş tayini metoduyla ilgili pek çok çalışma yapılmıştır (Castanet ve Baez, 1991; Mouton ve ark., 2005; Guarino ve ark., 2010; Pasko ve Borczyk, 2011; Kumaş, 2013; Gharzi ve Yari, 2013; Yakın ve Tok, 2015; Bülbül ve ark., 2016; Özdemir ve ark., 2017; Kumlutaş ve ark., 2018; Kalaycı ve ark., 2018; Kutrup ve ark., 2019; Üzüm ve ark., 2020). Ancak bu çalışmalar içerisinde bizim çalışmamızda kullanılmış türlerden alınan falanj, femur ve humerus kemiklerinde herhangi bir karşılaştırmalı yaş çalışmasına rastlanmamıștır.

Ülkemizde Lacerta trilineata ile yapılan yaş çalışmalarından; Kalaycı ve ark. (2018), Edirne ve Bolu'dan topladıkları örneklerde yaş ve boy bakımından karşılaştırma yapmışlardır. Bolu'daki örneklerin Edirne'deki örneklere göre ortalama yaşının daha büyük olduğu sonucuna varılmıştır. Kutrup ve ark. (2019), Sergen-Kırklareli'nden topladıkları örneklerde yaş ve boy karşılaştırması yapmışlardır. Hem dişilerde hem de erkek bireylerde yaş ve boy arasında önemli bir ilişki gözlemlenmemiştir. Büyüme oranına bakıldığında ise cinsiyetler arasında bir fark bulunmamıştır. Ophiops elegans ile yapılmış yaş çalışmalarından; Tok ve ark. (2013), Çanakkale ve Akşehir-Eber'den toplanan 
örnekleri karşılaştırmıştır. Akşehir-Eber populasyonunun yaş bakımından daha büyük olduğu sonucuna varılmıştır. Özdemir ve ark. (2017), Çanakkale ve Sivas populasyonları karşılaştırmıştır. Sivas populasyonu Çanakkale populasyonuna göre yaş ve boy bakımından daha büyük bulunmuş olsa da bu istatistiksel olarak anlamlı bulunmamıştır. Yaş ile boy arasındaki pozitif ilişki sadece Çanakkale populasyonu için geçerlidir. Parvilacerta parva ile yapılmış yaş çalışmalarından; Yakın ve ark. (2012), Akşehir-Eber, Konya'dan toplanan örnekleri yaş bakımından değerlendirmiştir. Dişi ve erkeklerde yaş-boy bakımından anlamlı pozitif bir korelasyon bulunmuştur. Özdemir ve ark. (2020), Sivas'tan toplanan örneklerde yaş ve boy kıyaslaması yapmıştır. Baş uzunluğu, baş genişliği ve vücut uzunluğunun ölçüldüğü bireylerde yaş ve boy arasında anlamlı bir ilişki bulunmuştur.

$\mathrm{Bu}$ çalışmada ise simpatrik yaşayan Lacertidae familyasına ait türler (Lacerta trilineata, Ophisops elegans ve Parvilacerta parva) ve bu türlere ait örneklerden alınan farklı kemikler karşılaştırmalı olarak incelenmiştir. $\mathrm{Bu}$ sayede bir türe ait aynı örnekte farklı kemikler arasında yaş halkalarının sayısı bakımından bir farklılığın olup olmadı̆̆ının araştırılması amaçlanmıştır.

\section{Materyal ve Metot}

Bu çalışmada, 2006 ve 2007 yılları arasında Konya iline bağlı Akşehir ve civarından toplanmış ve ZDEU-ÇOMÜ koleksiyonunda bulunan müze örnekleri kullanılmıştır. Yapılan çalışmada, $L$. trilineata (5ภ̂̉, 5 juvenil), O. elegans

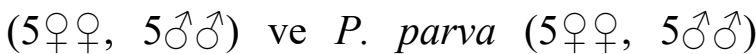
olmak üzere üç farklı türden toplam 30 örnek kullanılmıştır. Her bir örneğin vücut ölçümleri $0.01 \mathrm{~mm}$ hassasiyetli dijital kumpas kullanılarak ölçülmüştür. Tür bazında örnek sayısındaki azlık sebebiyle ortalama hesaplamalarında Microsoft Excel 2010 tanımlayıcı programı kullanılmıştır.

Çalışmada her bir örnekte sol arka ekstremitenin (zarar görmüş birkaç örnekte ise sağ arka ekstremiteden) dördüncü ayak parmağından alınan falanj, femur ve sol ön ekstremiteden (zarar görmüş birkaç örnekte ise sağ ön ekstremiteden) alınan humerus kemikleri çıkarılmıştır. Kemikler alındıktan sonra kalsiyumdan arındırmak için \%5'lik nitrik asit içerisine koyulmuştur. Her bir doku için, dokunun boyutuna göre değişen saat aralıklarında (falanj 3- 5 saat, humerus 3- 7 saat ve femurlar ise 4- 8 saat arasi) \%5'lik nitrik asit içinde bekletilmiştir. Yeterli sürede nitrik asit içerisinde kalan kemikler asitten arındırılmak için 24 saat boyunca akan su altında bekletilmiştir. Ardından dehidrasyon işlemi için artan alkol serileri $(\% 70,80,96$ ve absol) yapılmıştır. Devamında iki saat ksilen içinde 
bırakılmıştır. $\mathrm{Bu}$ işlemin ardından ksilenparafin içerisine alınarak bir gün boyunca bekletilmiş ve parafine gömülmüştür (McManus ve Mowry, 1964).

Kesitlerin alınmasında Leica 2125 RT marka mikrotom kullanılmıştır. Kalınlığı $14 \mu \mathrm{m}$ olan kesitler alınmıştır. Preparatlar Ehrlich's Hematoksilen \& Eosin ile boyanmış, Olympus CX21 marka 1ş1k mikroskobu ile incelenmiş ve Olympus BX51 marka 1şık mikroskobu ve Olympus Analysis LS programı ile fotoğraflanmıştır.

\section{Araştırma Sonuçları}

Konya iline bağlı Akşehir ve çevresinden toplanmış L. trilineata juvenillerinin SVL değerleri $41.18 \mathrm{~mm}$ ile $45.31 \mathrm{~mm}$ arasında değişmekte olup, yaşları 2 (Şekil 1) olarak tespit edilmiştir. Juvenillerde tespit edilen yaşların falanj, femur ve humerus kemiklerinde değişmediği, aynı olduğu gözlenmiştir. Aynı türün bir örneğinde yaş 5 olarak bulunurken SVL değeri $99.56 \mathrm{~mm}$ ölçülmüştür. Diğer erkek örnekler içerisinde ikisi 6 (Şekil 2) yaşında (SVL değerleri; $107.98 \mathrm{~mm}$ ve $112.18 \mathrm{~mm}$ ) ve birisi ise 7 yaşında (SVL değeri; $115.03 \mathrm{~mm}$ ) tespit edilmiştir. Bir örnek ise 8 yaşında olup, SVL değeri 116.18 mm'dir. Bu türe ait SVL ve yaş değerleri Çizelge 1'de gösterilmiştir. Tespit edilen tüm yaş değerleri falanj, femur ve humerus olmak üzere her üç kemikte de aynıdır.
Eldeki örneklere göre eşeysel olgunluk yaş1 ise 3 olarak tespit edilmiştir. Lacerta trilineata türü için o bölgeden toplanmış dişi birey bulunmadığından değerlendirme erkek bireyler arasında yapılmıştır.

Parvilacerta parva türünden ise 5 erkek, 5 dişi örnek değerlendirilmiştir. Değerler Çizelge 2'de gösterilmiştir. Erkek örneklerden üçü 4 (Şekil 3) yaşındadır (SVL değerleri; $49.21 \mathrm{~mm}, 49.78 \mathrm{~mm}$ ve 50.66 $\mathrm{mm})$. Diğer iki örneğin yaşı ise 5 olarak bulunmuştur ve SVL değerleri ise $52.02 \mathrm{~mm}$ ve $52.38 \mathrm{~mm}$ olarak ölçülmüştür. Dişi bireyler içerisinde bir örnekte yaş 4 olup, SVL değeri $44.69 \mathrm{~mm}$ olarak; iki örnek 5 yaşında olup, SVL değerleri $52.86 \mathrm{~mm}$ ve $53.08 \mathrm{~mm}$ olarak ölçülmüştür. İki örnekte ise yaş 6 (Şekil 4) olup, SVL ölçüleri 52.46 mm ve 56.31 mm'dir. Aynı türün tespit edilen tüm örneklerinde yaş değerleri çalışmada karşılaştırılan her üç kemik için benzer bulunmuştur.

Ophisops elegans türüne ait örneklerde de 5 erkek, 5 dişi birey değerlendirilmiştir. Bu değerler Çizelge 3'te gösterilmiştir. Erkek bireyler içerisinde bir bireyde yaş 4 olup, SVL değeri 46.15 mm'dir. İki bireyde 5 yaş gözlemlenmiş, SVL değerleri $47.56 \mathrm{~mm}$ ve $49.45 \mathrm{~mm}$ olarak ölçülmüştür. İki bireyde yaş 6'dır (Şekil 5). Bu örneklerin SVL değerleri 54.74 $\mathrm{mm}$ ve $55.54 \mathrm{~mm}$ olarak ölçülmüştür. Dişi örneklerden ikisinde yaş 5 (Şekil 6) olup, SVL değerleri $47.28 \mathrm{~mm}$ ile $48.23 \mathrm{~mm}$ 
olarak ölçülmüştür. İki örnekte yaş 6 olup, elegans türünden incelenen tüm SVL değerleri $51.70 \mathrm{~mm}$ ve $51.96 \mathrm{~mm}$ örneklerinde yaş değerleri çalışmada bulunmuştur. Bir örnekte ise 7 olup, SVL karşılaştırılan her üç kemik için benzer değeri ise $56.15 \mathrm{~mm}$ ölçülmüştür. Ophisops bulunmuştur.

Çizelge 1. Lacerta trilineata yaş ve SVL (baş+gövde) değerleri

\begin{tabular}{|c|c|c|c|c|c|}
\hline & Cinsiyet & Adet & Minimum & Maksimum & Ortalama \\
\hline \multirow{2}{*}{ SVL (mm) } & $\hat{\partial} \hat{\sigma}^{-1}$ & 5 & 99.56 & 116.18 & 110.18 \\
\hline & juvenil & 5 & 41.18 & 45.31 & 42.94 \\
\hline \multirow{2}{*}{ Yaş } & $\hat{\sigma} \hat{\sigma}$ & 5 & 5 & 8 & 6.4 \\
\hline & juvenil & 5 & 2 & 2 & 2 \\
\hline
\end{tabular}

(mm: milimetre)

Çizelge 2. Parvilacerta parva yaş ve SVL (baş+gövde) değerleri

\begin{tabular}{|c|c|c|c|c|c|}
\hline & Cinsiyet & Adet & Minimum & Maksimum & Ortalama \\
\hline \multirow{2}{*}{ SVL $(\mathrm{mm})$} & $\hat{\partial} \hat{\theta}$ & 5 & 49.21 & 52.38 & 50.81 \\
\hline & 우우 & 5 & 44.69 & 56.31 & 51.88 \\
\hline \multirow{2}{*}{ Yaş } & $\hat{\partial} \sigma^{\lambda}$ & 5 & 4 & 5 & 4.4 \\
\hline & 우우 & 5 & 4 & 6 & 5.2 \\
\hline
\end{tabular}

(mm: milimetre)

Çizelge 3. Ophisops elegans yaş ve SVL (baş+gövde) değerleri

\begin{tabular}{|c|c|c|c|c|c|}
\hline & Cinsiyet & Adet & Minimum & Maksimum & Ortalama \\
\hline \multirow{2}{*}{ SVL (mm) } & $\hat{\partial} \hat{\sigma}$ & 5 & 46.15 & 55.54 & 50.68 \\
\hline & 우우 & 5 & 47.28 & 56.15 & 51.06 \\
\hline \multirow{2}{*}{ Yaș } & $\hat{\partial}$ & 5 & 4 & 6 & 5.2 \\
\hline & 우 & 5 & 5 & 7 & 5.8 \\
\hline
\end{tabular}

(mm: milimetre)

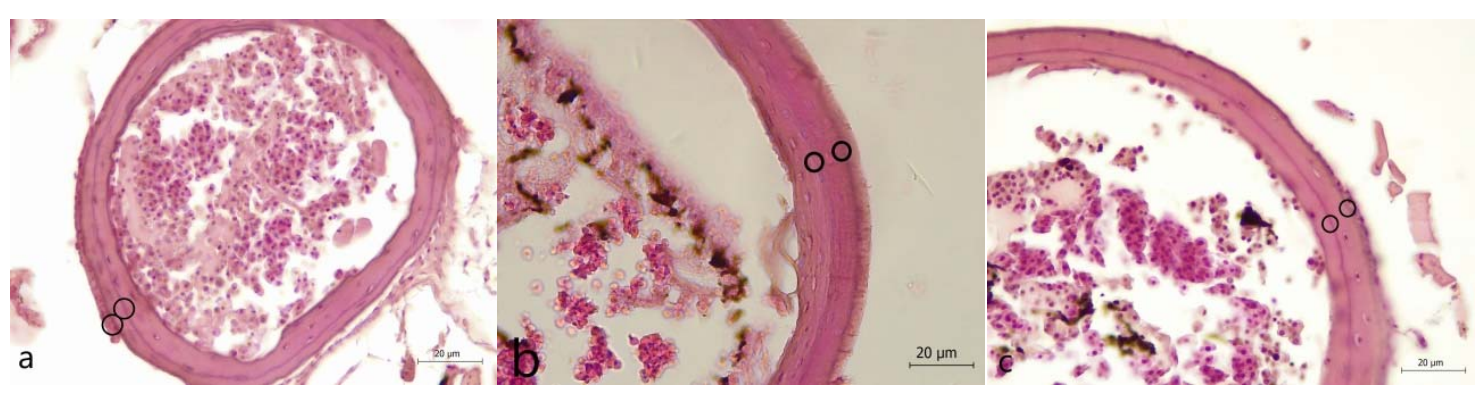

Şekil 1. Lacerta trilineata juvenil 2 yaş örnekleri (a. falanj, b. femur, c. humerus)

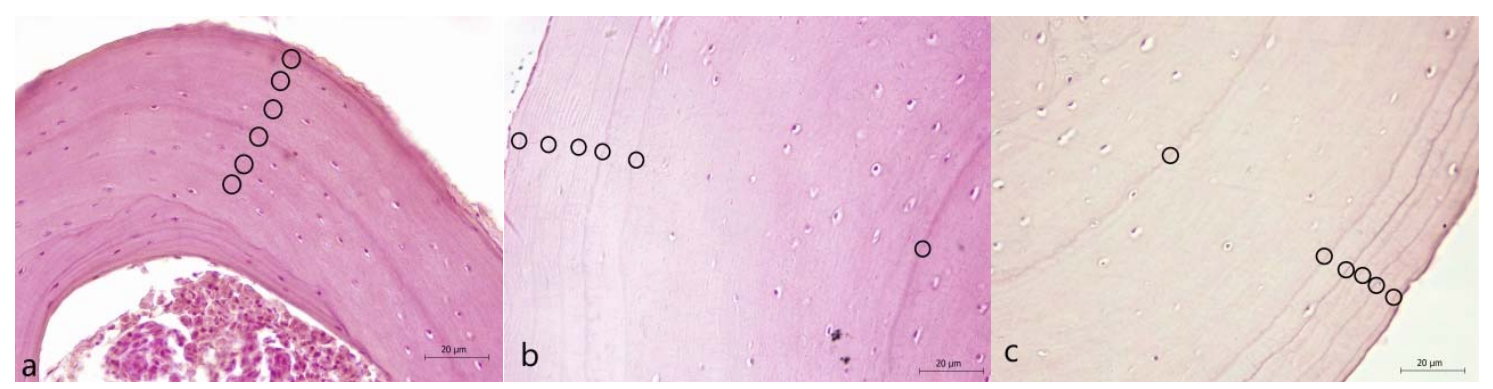


Şekil 2. Lacerta trilineata erkek birey 6 yaş örnekleri (a. falanj, b. femur, c. humerus)

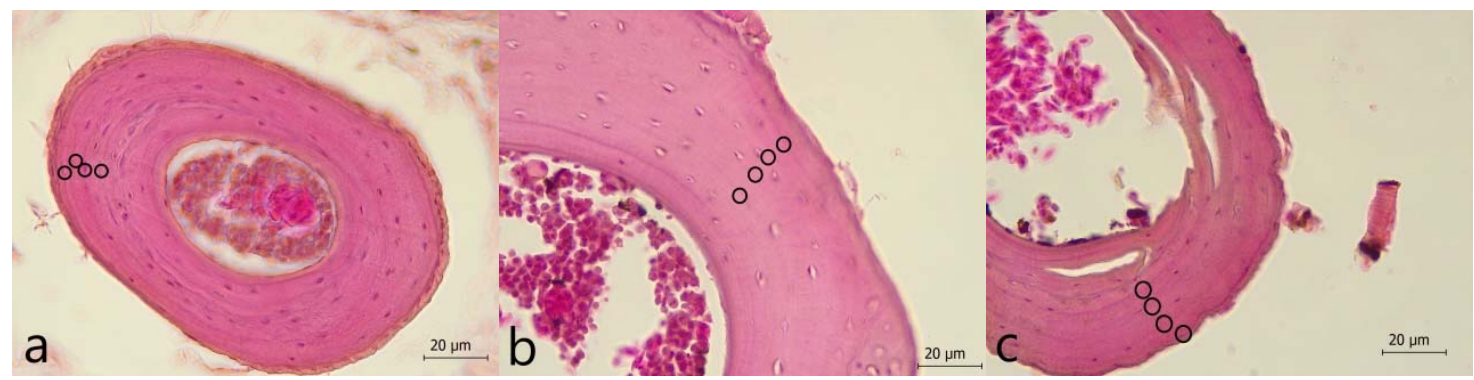

Şekil 3. Parvilacerta parva erkek birey 4 yaş örnekleri (a. falanj, b. femur, c. humerus)

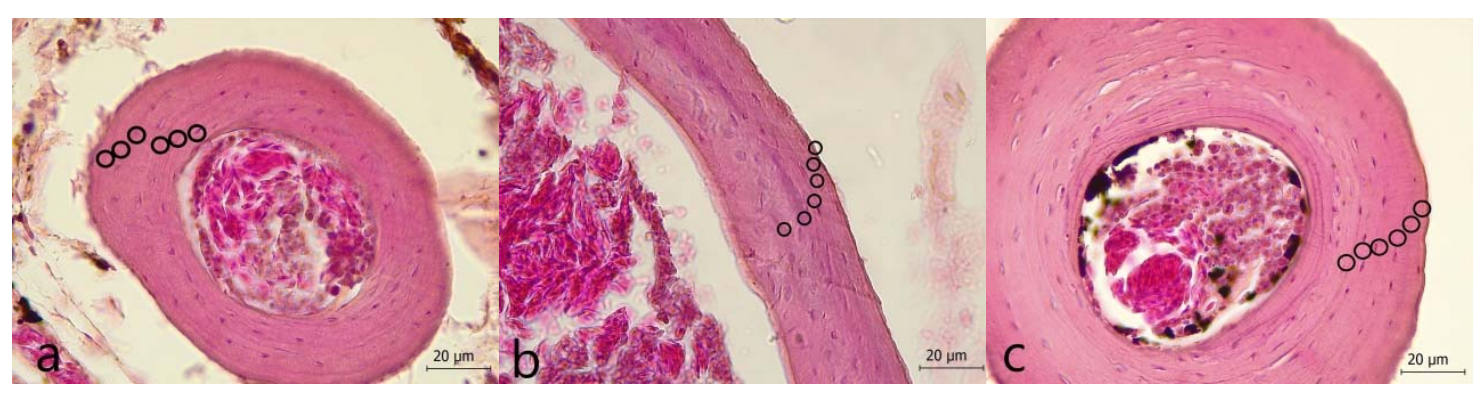

Şekil 4. Parvilacerta parva dişi birey 6 yaş örnekleri (a. falanj, b. femur, c. humerus)

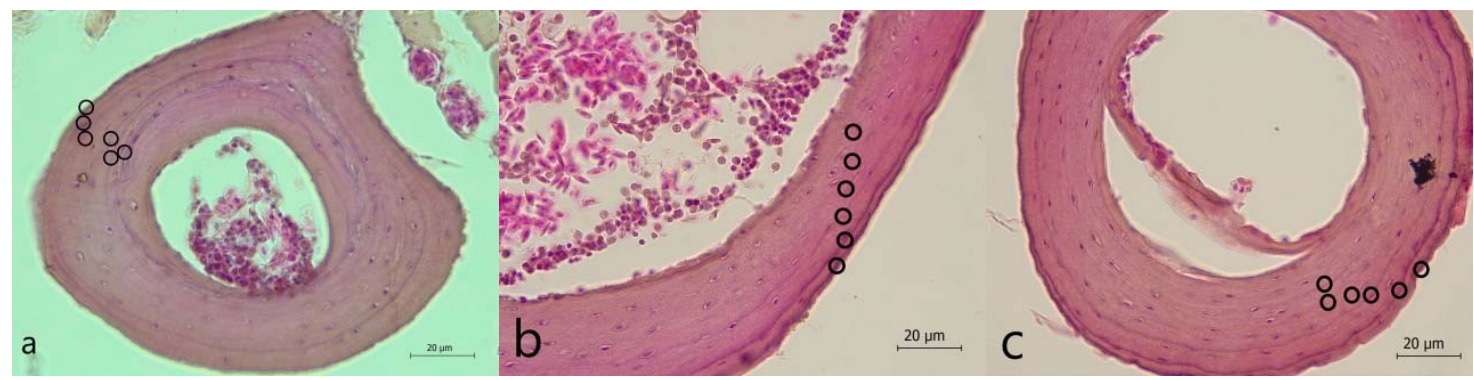

Şekil 5. Ophisops elegans erkek birey 6 yaş örnekleri (a. falanj, b. femur, c. humerus)

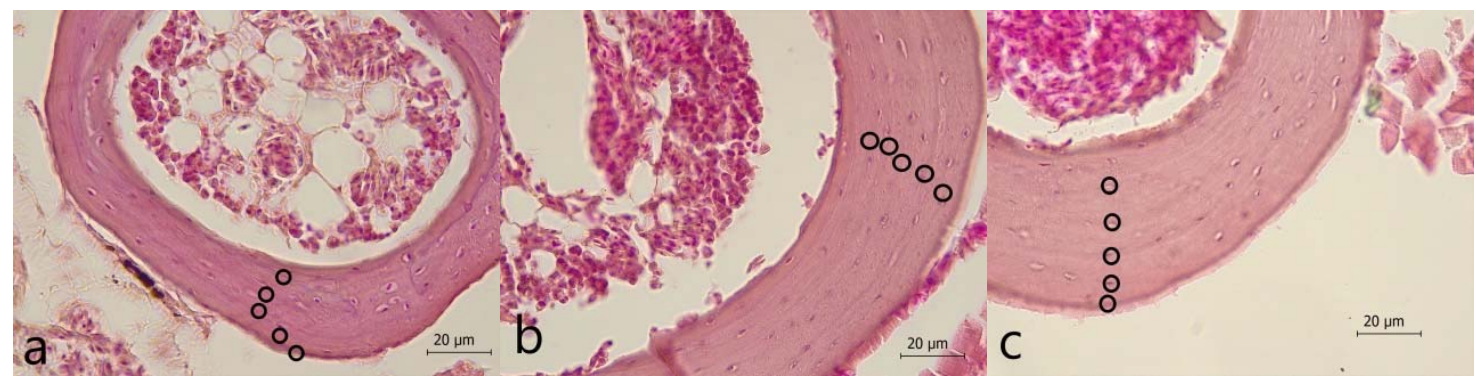

Şekil 1. Ophisops elegans dişi birey 5 yaş örnekleri (a. falanj, b. femur, c. humerus)

\section{Tartışma}

Bulunan sonuçlar neticesinde değerlendirilen örneklerin falanj, femur ve humerus kemiklerinde gözlenen yaşlar arasında herhangi bir fark bulunmamıştır.
Kutrup ve ark. (2019) yaptıkları bir çalışmada $L$. trilineata türünün yaşını değerlendirmiş̧tir. Bu çalışmada, Kırklareli bölgesinden topladıkları 14 erkek ve 12 dişi bireyle çalışılmıştır. Sadece falanj kemikleri ile çalıştıklarından parmak alındıktan sonra 
bireyleri habitatlarına geri bırakılmıştır. Eşeysel olgunluk yaşının her iki cinsiyette de 3 yıl olarak bulunduğu çalışmada dişi bireylerde en büyük yaş 10, erkek bireylerde ise $13 \mathrm{y} 1 \mathrm{l}$ olarak tespit edilmiştir. Dişi bireylerde ortalama 8 yaşında olan bireyin SVL değerini $108.51 \mathrm{~mm}$ olarak bulurken erkek bireylerde ortalama 9 yaşındaki bireylerin SVL değerleri $110.12 \mathrm{~mm}$ ölçülmüştür. Dişi ve erkek bireylerde gözlemlenen bu faklılı̆̆ın çevresel faktörlerden kaynaklandığg belirtilmiştir. Bu çalışmada değerlendirilen bölgedeki örnekler içerisinde $L$. trilineata erkek bireyleriyle karşılaştırıldığında bizim az sayıdaki örneğimizde en büyük yaş 8 olup, bu bireyin SVL değeri $116.18 \mathrm{~mm}$ olarak ölçülmüştür. $\mathrm{Bu}$ çalışmaya göre bizim çalışmamızdaki örneklerin yaşları daha küçük olmasına rağmen boy olarak daha büyük olduğu görülmektedir. Bunun sebebinin iklim farklılığ 1 ve yükseltiye bağl1 değiştiği söylenebilir (Boretto ve ark., 2018).

Kalaycı ve ark. (2018) yaptıkları bir çalışmada Edirne (17 m) ve Bolu (1250 m) bölgesinden toplanmış olan $L$. trilineata örneklerini değerlendirmiştir. Her iki bölgeden de toplanmış olan bireylerin eşeysel olgunluk yaşları 2 yıl olarak tespit edilmiştir. Bolu örneklerinde en büyük erkek birey 6, en büyük dişi birey de 7 yaşında bulunmuştur. Edirne örneklerinde ise en büyük erkek 5 , en büyük dişi de 4 yaşında bulunmuştur. $\mathrm{Bu}$ sonuçlar neticesinde yüksek yerlerde yaşayan erkek bireylerin daha geç olgunlaştığı ancak azalan oksijen sebebiyle boylarının daha küçük olduğu kanaatine varılmıştır. $\mathrm{Bu}$ çalışmada da $L$. trilineta juvenillerinin yaşları 2 olarak bulunmuş olup SVL değerleri birbirine benzerdir. Erkek bireylerde ise SVL değerleri yaşla birlikte doğru orantılı olarak artmıştır.

Yakın ve ark. (2012) Konya, Akşehir'den toplanmış $14 \operatorname{adet}(5 \hat{\jmath} \widehat{\jmath}, 9$ 9 + ) ZDEU- ÇOMÜ koleksiyonundan $P$. parva örneklerinin femurlarında iskelet kronolojisi yöntemiyle yaş yapısını değerlendirmiştir. Dişi bireylerde maksimum yaş 8 yıl iken erkeklerde 7 y1l olarak tespit edilmiştir. Erkek bireylerin SVL değerleri 46.92 mm$52.51 \mathrm{~mm}$ arasında bulunmuştur. Dişi bireylerin SVL değerleri 47.98 mm- 58.62 mm olarak ölçülmüştür. Dişi bireylerin SVL değerleri erkek bireylere göre daha büyük bulunmuştur. Pileus uzunluğu ise tam tersi erkeklerde dişilere göre daha büyüktür. Bizim çalışmamızda da dişi bireyler ile erkekler karşılaştırıldığında dişilerin daha büyük olduğu gözlemlenmiştir. Yine bu çalışmayla benzer olarak pileus uzunluğu bizim çalışmamızda da erkeklerde daha büyük ölçülmüştür. $\mathrm{Bu}$ iki çalışma aynı bölgenin aynı türleriyle yapılmış olduğundan böyle bir benzerlik beklendik bir durumdur. 
Özdemir ve ark. (2020) Sivas'tan topladikları 24 adet $(21 q q, 3 \hat{\jmath}) P$. parva bireyi ile yaptıkları yaş çalışmasında hayvanların parmak (falanj) kemiklerini kullanmışlardır. $\mathrm{Bu}$ çalışmada dişilerde maksimum yaş 7 yıl iken erkeklerde 6 yıl olarak bulunmuştur. Dişilerin SVL değerleri $31.18 \mathrm{~mm}-58.76 \mathrm{~mm}$ ve erkeklerin SVL değerleri $47.70 \mathrm{~mm}-52.82 \mathrm{~mm}$ olarak ölçülmüştür. Yüksek bölgelerde hava daha soğuk olduğundan sürüngenlerin aktif dönemleri kısadır. Bu sebeple büyümeleri de yavaş olur. Sivas populasyonunun Konya populasyonuna göre daha küçük ebatlarda ve yaşta olmalarının sebebi de bu şekilde yorumlanmaktadir.

Tok ve ark. (2013) Akşehir- Eber, Konya'dan toplanmış olan 43 adet $(23 \widehat{\jmath}$, 20 우) Ophisops elegans ile Çanakkale'den


populasyonlarında yaş çalışması yapmıştır. $\mathrm{Bu}$ çalışma kertenkelelerin femurları kullanılarak yapılmıştır. Çanakkale populasyonunda dişi bireylerin SVL değerlerini $38.41 \mathrm{~mm}$ - $52.63 \mathrm{~mm}$, erkek bireylerin SVL değerleri $40.54 \mathrm{~mm}-50.52$ mm olarak ölçülmüştür. Akşehir-Eber populasyonunda ise dişilerin SVL değerleri $46.62 \mathrm{~mm}-53.47 \mathrm{~mm}$ iken erkeklerinki ise $46.70 \mathrm{~mm}-50.35 \mathrm{~mm}$ olarak ölçülmüştür. Akşehir- Eber populasyonunda en büyük yaş 6 olarak bulunurken Çanakkale populasyonunda 4 olarak bulunmuştur.
Akşehir- Eber örnekleri bizim çalışmamızdaki O.elegans örnekleri ile hem yaş hem de boyut bakımından benzerlik göstermektedir. Akşehir- Eber, Çanakkale'ye göre daha yüksek bir konumda olduğundan hava sicaklığ1 düşüktür. Bu sebeple kertenkelelerin yüksek yerlerde gelişimi daha geç olmaktadır.

Özdemir ve ark. (2017) O. elegans türünün Sivas $(1595 \mathrm{~m})$ populasyonu ile Çanakkale $(7 \mathrm{~m})$ populasyonu arasındaki yaş ve SVL farklılıklarını incelemişlerdir. Çanakkale populasyonunun dişi bireylerinde SVL $34.41 \mathrm{~mm}-74.51 \mathrm{~mm}$ arasında iken erkeklerde $36.23 \mathrm{~mm}-47.87 \mathrm{~mm}$ arasında ölçülmüştür. Dişiler 3-7 yıl aralığında bulunmuşken erkekler 3- 6 yıl aralığında tespit edilmiştir. Dişilerin yaş ortalamasının erkeklerden daha yüksek olduğu kanaatine varılmıştır. Dişilerde yaş ve SVL değeri arasında anlamlı bir korelasyon bulunurken erkeklerde bu ilişki anlamlı bulunmamıştır. Sivas populasyonunda dişilerin SVL aralığ1 $43.14 \mathrm{~mm}-73.66 \mathrm{~mm}$ iken erkeklerde bu aralık $54.00 \mathrm{~mm}-76.70 \mathrm{~mm}$ olarak ölçülmüştür. Dişiler 3- 6 yaş aralığında erkekler ise 4- 8 yaş aralığında tespit edilmiştir. Çanakkale populasyonuna ait dişilerin yaş ortalaması Sivas'a göre daha yüksek iken boy uzunlukları daha küçük bulunmuştur. Erkek bireylerde ise Sivas populasyonunda yaş ve boy uzunluğu bakımından Çanakkale populasyonuna göre 
daha yüksek değerler olduğu saptanmıştır. Sivas populasyonunun yaş ortalamasının Çanakkale populasyonuna göre yüksek olmasının istatistiksel olarak anlamlı bulunmadığı sonucuna varılmıştır. Yaş ile boy arasında pozitif ilişkiyi sadece Çanakkale populasyonunun dişi bireylerinde tespit etmişlerdir. Her iki populasyon içinde erkek bireylerin yaş-boy ilişkisinin anlamsız bulunması sayıca az olmalarından kaynaklanabileceği sonucu çıkarılmıştır. Sivas ile bu çalışmada yer alan AkşehirKonya arasında rakım olarak fazla fark bulunmadığından Sivas populasyonu ile Konya populasyonu bazı yaş ve SVL değerleri bakımından benzer bulunmuştur.

Comas ve ark.

Psammodromus algirus bireylerinde "İskelet kronolojisi" yöntemiyle falanj, femur ve humerus kemikleri arasında karşılaştırmalı yaş çalışması yapmıştır. İlgili türden 14 adet birey kullanılmıştır. Tespit edilen sonuçlar neticesinde üç ayrı kemikte de yaşlar aynı bulunmuştur. $\mathrm{Bu}$ nedenle özellikle nesli tehlikede olan türler için yaş çalışması yapılmak istendiğinde bunun bireyi öldürmeden sadece falanj kemikleriyle yapılmasının mümkün olduğu belirtilmiştir. Elde edilen sonuçlar bu çalışmadaki sonuçlar ile benzerlik göstermektedir.

Kumaş (2013) Stellagama stellio bireylerinde falanj, femur ve humerus kemikleri ile karşılaştırmalı yaş tayini yapmıştır. Dişi bireylerde yaş aralığı 1-4 yıl iken erkek bireylerde 1-5 y1l olarak bulunmuştur. Femur ve humerus kemiklerinde yaşlar ortak bulunurken falanj kemiklerinde femur ve humerustan bir eksik olarak tespit edilmiştir. Ancak geri hesaplama ile falanj kemiklerinde endosteal resorpsiyon sonucu bir halkanın tamamen kaybolmadığı gözlenmiştir. $\mathrm{Bu}$ nedenle yaş tayini için en uygun kemikler femur ve humerus olmasına rağmen falanj kemiği de doğru sonuçlar verdiğinden yaş çalışmalarında kullanılabileceği belirtilmiştir.

Varela ve Cabrera

Tupinambis merianae (Salvator merianae) bireylerinde yaş çalışması yapmıştır. Toplam 17 adet humerus ve 30 adet falanj ile çalışarak karşılaştırma yapılmıştır. Sonuçlar değerlendirildiğinde karşılaştırma yapılan bu iki kemik arasında yaş bakımından büyük oranda benzerlik bulunmuştur. $\mathrm{Bu}$ sebeple yaş tayini çalışmalarında falanj kemiklerinin kullanımı hem bireylerin öldürülmesini önlemek hem de gelecek yıllarda nesillerin büyümesinin izlenebilmesi açısından önemli olduğu sonucuna varılmıștır.

$\mathrm{Bu}$ çalışmada kemikler arasında herhangi bir farklılık görülmemiştir (Şekil 1, Şekil 2, Şekil 3, Şekil 4, Şekil 5 ve Şekil 6). Bundan sonraki yaş çalışmaları için türleri öldürmeden sadece parmak kemiklerini alarak canlının tekrar habitatına bırakılmasıyla çalışmaların yapılabileceği 
düşünülmektedir. Böylece söz konusu türlerin neslinin devamını tehlikeye sokmadan, hayvanları öldürmeden parmaktan alınan kemiklerle farklı populasyonlarında yaş çalışmalarının yapılmasının ve yaşam uzunlukları hakkında gerekli bilgilerin elde edilmesinin mümkün olduğuna inanılmaktadır.

\section{Teşekkür}

$\mathrm{Bu}$ çalışma Çanakkale Onsekiz Mart Üniversitesi Lisansüstü Eğitim Enstitüsü'nde tamamlanmış bir Yüksek Lisans tezidir. Laboratuvar çalışmalarındaki desteğinden dolayı Dr. Batuhan Yaman YAKIN'a teşekkür ederim.

\section{Kaynaklar}

Baran İ, Ilgaz Ç, Avcı A, Kumlutaş Y, Olgun K (2012). Türkiye Amfibi ve Sürüngenleri. TÜBİTAK, Ankara.

Başoğlu B, Baran İ (1977). Türkiye Sürüngenleri, Kısım 1. Kaplumbağa ve Kertenkeleler. İlker Matbaa, Bornova-İzmir.

Boretto JM, Cabezas-Cartes F, Ibargüengoytia NR (2018). Slow life histories in lizards living in the highlands of the Andes Mountains. Journal of Comparative Physiology 188: 491503.

Bülbül U, Kurnaz M, Eroğlu Aİ, Koç H, Kutrup B (2016). Age and growth of the red-belied lizard, Darevskia parvula. Animal Biology 66: 81-95.

Castanet J, Baez M (1991). Adaptation and evolution in Gallotia lizards from the Canary Islands: age, growth, maturity and longevity. Amphibia-Reptilia 12: 81-102.

Comas M, Reguera S, Zamora-Camacho FJ, Salvado H, Moreno-Rueda G (2016). Comparison of the effectiveness of phalanges vs. humeri and femurs to estimate lizard age with skeletochronolgy. Animal Biodiversity and Conservation 39(2): 237-240.

Gharzi A, Yari A (2013). Age determination in the Snake-eyed Lizard, Ophisops elegans, by means of skeletochronology (Reptilia: Lacertidae). Zoology in the Middle East 59 (1): $10-15$.

Guarino FM, Gia ID, Sindaco R (2010). Age and growth of the sand lizards (Lacerta agilis) from a high alpine population of North-Western Italy. Acta Herpetologica, 5(1): 23-29.

https://www.iucnredlist.org (Erişim Tarihi: 15.03.2021)

https://lacerta.de/AS/Home.php (Erişim Tarihi: 15.03.2021)

Kalaycı TE, Gül Ç, Tosunoğlu M, Özdemir N (2018). On the age structure of two samples of Lacerta trilineata BedriaGa, 1886, from different altitudes in Turkey. Herpetozoa 31 (1/2): 3-9.

Kumaş M (2013). Türkiye'deki Laudakia stellio (Linnaeus, 1758) (Reptilia: Sauria: Agamidae) populasyonlarında yaş tayini ve uzun kemik histolojisi. Doktora Tezi, Ege Üniversitesi Fen Fakültesi Biyoloji Bölümü, İzmir, Türkiye. 
Kumlutaş Y, Üzüm N, Avcı A, Güler H, Ilgaz Ç, Candan K (2018). Comparison of the body size and age structure of Lebanon lizard, Phoenicolacerta laevis (Gray, 1838) at different altitudes in Turkey. Vertebrate Zoology 68(1): 83-90.

Kutrup B, Odabaş Y, Bülbül U, Eroğlu A İ, Koç H, Kurnaz M (2019). Age structure and growth in a Turkish population of the Balkan Green Lizard, Lacerta trilineata BedriaGa, 1886. Herpetozoa 31 (3/4): 183-193.

McManus JFA, Mowry RW (1964). Staining methods: Histologic and histochemical. Ist ed. London, UK: Hoeber International.

Mouton P.le Fras N, Curtin AJ, Chinsamy A (2005). Bone growth patterns in two cordylid lizards, Cordylus cataphractus and Pseudocordylus capensis. African Zoology 40(1): 17.

Özdemir N, Altunışık A, Kalaycı TE, Uysal İ, Tosunoğlu M (2017). Tarla kertenkelesi (Ophisops elegans) (Sauria: Lacertidae)'nin farklı rakımlarda yaşayan iki populasyonunda yaş tayini. Anadolu Çevre ve Hayvancıllk Bilimleri Dergisi 1: 11-14.

Özdemir N, Kalaycı TE, Uysal İ, Gül Ç (2020). Body size and age structure of the Parvilacerta parva (Boulenger, 1887) population from Sivas, Turkey. Iğdır Üniversitesi Fen Bilimleri Enstitüsü Dergisi 10(1): 39-44.

Pasko L, Borczyk B (2011). How precise are size-based age estimations in the sand lizard (Lacerta agilis)? Zoologica Poloniae 56(1-4): 11-17.

Tok CV, Hayretdă̆ S, Gürkan M, Yakın BY (2013). Age determination in some Ophisops elegans Mènètriès 1832 (Sauria: Lacertidae) populations living in the vicinity of Çanakkale and Akşehir-Eber. Ecologia Balkanica 5(2): 23-30.

Üzüm N (2006). Türkiye'deki Triturus karelinii (Strauch 1870) (Urodela: Salamandridae) Populasyonlarında yaş tayini: populasyonların büyüme, yaş ve boy bakımından karşılaştırılması. Doktora Tezi, Adnan Menderes Üniversitesi Fen Bilimleri Enstitüsü, Aydin, 182.

Üzüm N, Beşer N, Ilgaz Ç, Kumlutaş Y, Candan K, Güçlü Ö (2020). Age and growth in two populations of Danford's lizard, Anatololacerta danfordi (Günther, 1876), from the eastern Mediterranean. Turkish Journal of Zoology 44: 173-180.

Varela CFD, Cabrera MR (2000). Testing skeletochronology in black tegu lizards (Tupinambis merianae) of known ages. Herpetological Review 31 (4).

Yakın BY, Tok CV, Hayretdağ S, Gürkan M (2012). Preliminary data on age estimation and body size of the dwarf lizard, Parvilacerta parva (Boulenger, 1887) (Reptilia: Lacertilia) from Akşehir, Konya (Turkey). Ecologia Balkanica 4(1): 81-85.

Yakın BY, Tok CV (2015). Age estimation of Anatololacerta anatolica (Werner, 1902) in the vicinity of Çanakkale by skeletochronology. Turkish Journal of Zoology 39: 66-73.

Yaşar Ç, Çiçek K, Mulder J, Tok CV, (Baskıda). The distribution and biogeography of Amphibians and Reptiles in Turkey. North Western Journal of Zoology 2020, e201512. 